\title{
Comparison of the Time Courses of Insulin and the Portal Signal on Hepatic Glucose and Glycogen Metabolism in the Conscious Dog
}

\author{
Michael J. Pagliassotti, Linda C. Holste, Mary C. Moore, Doss W. Neal, and Alan D. Cherrington \\ Department of Molecular Physiology and Biophysics, Vanderbilt University School of Medicine, Nashville, Tennessee 37232
}

\begin{abstract}
To investigate the temporal response of the liver to insulin and portal glucose delivery, somatostatin was infused into four groups of 42-h-fasted, conscious dogs ( $n=6$ /group), basal insulin and glucagon were replaced intraportally, and hyperglycemia was created via a peripheral glucose infusion for $90 \mathrm{~min}$ (period 1). This was followed by a 240-min experimental period (period 2) in which hyperglycemia was matched to period 1 and either no changes were made (CON), a fourfold rise in insulin was created (INS), a portion of the glucose $\left(22.4 \mu \mathrm{mol} \cdot \mathrm{kg}^{-1} \cdot \mathrm{min}^{-1}\right)$ was infused via the portal vein (Po), or a fourfold rise in insulin was created in combination with portal glucose infusion (INSPo). Arterial insulin levels were similar in all groups during period 1 $(\sim 45 \mathrm{pM})$ and were $45 \pm 9,154 \pm 20,43 \pm 7$, and $128 \pm 14 \mathrm{pM}$ during period 2 in CON, INS, Po, and INSPo, respectively. The hepatic glucose load was similar between periods and among groups $\left(\sim 278 \mu \mathrm{mol} \cdot \mathrm{kg}^{-1} \cdot \mathrm{min}^{-1}\right)$. Net hepatic glucose output was similar among groups during period 1 $\left(\sim 0.1 \mu \mathrm{mol} \cdot \mathrm{kg}^{-1} \cdot \mathrm{min}^{-1}\right)$ and did not change significantly in CON during period 2. In INS net hepatic glucose uptake (NHGU; $\mu \mathrm{mol} \cdot \mathrm{kg}^{-1} \cdot \mathrm{min}^{-1}$ ) was $-3.8 \pm 3.3$ at $15 \mathrm{~min}$ of period 2 and did not reach a maximum $(-15.9 \pm 6.6)$ until 90 min. In contrast, NHGU reached a maximum of $-13.0 \pm 3.7$ in Po after only $15 \mathrm{~min}$ of period 2. In INSPo, NHGU reached a maximum $(-23.6 \pm 3.5)$ at $60 \mathrm{~min}$. Liver glycogen accumulation during period 2 was $21 \pm 10,84 \pm 17,65 \pm 16$, and 134 $\pm 17 \mu \mathrm{mol} / \mathrm{gram}$ in CON, INS, Po, and INSPo, respectively. The increment (period 1 to period 2 ) in the active form of liver glycogen synthase was $0.7 \pm 0.4,6.5 \pm 1.2$, $2.8 \pm 1.0$, and $8.5 \pm 1.3 \%$ in CON, INS, Po, and INSPo, respectively. Thus, in contrast to insulin, the portal signal rapidly activates NHGU. In addition, the portal signal, independent of a rise in insulin, can cause glycogen accumulation in the liver. (J. Clin. Invest. 1996. 97:81-91.) Key words: liver $\bullet$ hyperglycemia $\bullet$ glycogen synthase
\end{abstract}

\section{Introduction}

Net hepatic glucose uptake (NHGU) ${ }^{1}$ is negligible in the presence of hyperinsulinemia and hyperglycemia, when the latter

Address correspondence to Michael J. Pagliassotti, University of Colorado Health Sciences Center, Department of Pediatrics, Section of Pediatric Nutrition, 4200 E. Ninth Ave., Campus Box C225, Denver, CO 80262. Phone: 303-270-5609; FAX: 303-270-3273.

Received for publication 11 January 1995 and accepted in revised form 30 August 1995.

J. Clin. Invest.

(c) The American Society for Clinical Investigation, Inc.

0021-9738/96/01/0081/11 \$2.00

Volume 97, Number 1, January 1996, 81-91 results from a peripheral glucose infusion (1-3). In humans, the combination of hyperglycemia $(175-225 \mathrm{mg} / \mathrm{dl}$ in arterial plasma) and hyperinsulinemia (40-55 $\mu \mathrm{U} / \mathrm{ml}$ in arterial plasma) produced rates of net splanchnic glucose uptake of $1.0-1.6 \mathrm{mg} / \mathrm{kg} / \mathrm{min}(2,3)$. In the dog, arterial plasma glucose levels of $160-290 \mathrm{mg} / \mathrm{dl}$ and insulin levels of $35-384 \mu \mathrm{U} / \mathrm{ml}$ resulted in rates of NHGU of $1.0-2.9 \mathrm{mg} / \mathrm{kg} / \mathrm{min}$ (1). These results demonstrate that the combination of hyperinsulinemia and hyperglycemia cannot account for the peak rates of NHGU (up to $7.5 \mathrm{mg} / \mathrm{kg} / \mathrm{min}$ ) present after the ingestion of glucose in either humans or the $\operatorname{dog}(1,4-9)$. In addition to the rise in insulin and glucose, meal ingestion also produces a rise in the portal vein glucose level that is greater than the glucose level in the arterial circulation. This gradient of glucose is specific to the postprandial setting and is not present when glucose is infused into a peripheral vein. Several studies have clearly demonstrated that this negative arterial-portal glucose gradient (or portal signal) can increase NHGU in the presence of hyperglycemia and hyperinsulinemia to rates that are comparable to those observed after glucose ingestion $(1,10)$. In this context, the portal signal allows the liver to distinguish between ingested and internally derived glucose.

After the ingestion of a high-carbohydrate-containing meal, the liver switches rapidly $(<15 \mathrm{~min})$ into net glucose uptake (4). This shift to glucose uptake suggests that one or more of the above signals can rapidly induce net glucose uptake by the liver. Although insulin and glucose levels rise rapidly after a meal, the hepatic actions of hyperglycemia and hyperinsulinemia are relatively slow in onset $(11,12)$. Indirect evidence that the portal signal may rapidly activate liver glucose uptake is suggested by the fact that the augmentation of NHGU produced by the portal signal is abolished in dogs that have undergone complete hepatic surgical denervation (13). If the hepatic response to portal activation involved a neural loop, one would predict that both the transmission of the signal and the hepatic response would be rapid. Thus, in addition to its role in alerting the liver to the presence of ingested glucose, the portal signal may induce the rapid shift of the liver into glucose sequestration after meal ingestion. One aim of this study was to directly compare the time course in the transition of liver glucose metabolism (output to uptake) in response to glucose, insulin, and the portal signal.

Hepatic glycogen repletion after a meal occurs by both a

1. Abbreviations used in this paper: $\mathrm{CF}$, correction factor; $\mathrm{CON}$, hyperglycemic control group; CV, coefficient of variation; Endo Ra, endogenous glucose production; GUG, uptake of glucose by the gastrointestinal tract; HBF, hepatic blood flow; HGU, hepatic glucose uptake; INS, hyperinsulinemic, hyperglycemic group; INSPo, combined hyperinsulinemia and portal glucose infusion group; NHGB, net hepatic glucose balance; NHGU, net hepatic glucose uptake; PAH, $p$-aminohippuric acid; PBF, portal blood flow; Po, portal glucose infusion group; SA, specific activity. 
direct pathway through glucose-1-phosphate and uridine diphosphate glucose and an indirect pathway utilizing gluconeogenic precursors (14). The contribution of the direct pathway to hepatic glycogen synthesis has been estimated to be between 35 and $70 \%(14-19)$. Some studies have suggested that the gluconeogenic precursors used for glycogen synthesis via the indirect pathway may arise within the liver from glucose carbon that is glycolyzed and converted back to glycogen (19). The ability of the portal signal to augment NHGU in the presence of hyperglycemia and hyperinsulinemia suggests that it may also be an important regulator of hepatic glycogen synthesis from both of these pathways. The second aim of this study was to investigate the ability of the portal signal to cause hepatic glycogen accumulation and to determine the extent to which activation of hepatic glycogen synthase occurred in response to glucose, insulin, and the portal signal.

\section{Methods}

Animals and surgical procedures. Studies were carried out on 52 42h-fasted, conscious mongrel dogs of either sex, weighing between 24 and $30 \mathrm{~kg}$. A fast of this duration was chosen because it produces a metabolic state resembling that in the overnight-fasted human (the liver exhibits net lactate uptake) and results in liver glycogen levels in the dog that are at a stable minimum (20). All animals were maintained on a diet of meat (Kal Kan, Vernon, CA) and chow (Purina Lab Canine Diet No. 5006; Ralston Purina Co., St. Louis, MO) composed of $34 \%$ protein, $14.5 \%$ fat, $46 \%$ carbohydrate, and $5.5 \%$ fiber based on dry weight. The animals were housed in a facility which met American Association for Accreditation of Laboratory Animal Care guidelines, and the protocol was approved by the Vanderbilt University Medical Center Animal Care Committee.

Approximately $16 \mathrm{~d}$ before study, each dog underwent a laparotomy under general anesthesia (pentobarbital sodium $25 \mathrm{mg} / \mathrm{kg}$, or isoflurane $0.8 \%$ ) during which catheters were inserted into a hepatic vein, the hepatic portal vein, and a femoral artery as described in detail elsewhere $(1,8)$. Catheters were also placed in a splenic and a jejunal vein. Doppler flow probes (Instrumentation Development Laboratories, Baylor College of Medicine, Houston, TX) were placed around the portal vein and the hepatic artery (21). The catheters were filled with saline containing heparin $(200,000 \mathrm{U} /$ liter; Abbott Laboratories, North Chicago, IL), their free ends were knotted, and they, along with the free ends of the Doppler leads, were placed in a subcutaneous pocket so that complete closure of the incisions was possible.

Approximately $2 \mathrm{~d}$ before study, blood was drawn to determine the leukocyte count and the hematocrit of each animal. The dog was studied only if it had a leukocyte count $<18,000 / \mathrm{mm}^{3}$, a hematocrit $>35 \%$, a good appetite as evidenced by consumption of all of the daily ration, and normal stools.

On the morning of the study, catheters and Doppler leads were exteriorized from their subcutaneous pocket using local anesthesia (20 grams/liter Lidocaine; Astra Pharmaceuticals, Worcester, MA). The contents of each catheter were aspirated, and the catheters were flushed with saline. The splenic and jejunal catheters were used for intraportal infusion of insulin and glucagon (Eli Lilly \& Co., Indianapolis, IN), glucose, and $p$-aminohippuric acid (PAH; Sigma Immunochemicals, St. Louis, MO). PAH was used to assess mixing of glucose in the portal and hepatic veins during intraportal glucose infusions. Portal vein, hepatic vein, and femoral artery catheters were used for blood sampling. Angiocaths (Deseret Medical, Becton Dickinson, Sandy, UT) were inserted into the left cephalic vein for $3-{ }^{3} \mathrm{H}$-glucose and indocyanine green infusion (Hynson, Westcott, and Dunning, Baltimore, MD), the right cephalic vein for peripheral glucose infusion, and the right saphenous vein for somatostatin (Bachem California, Torrance, CA) and PAH infusions. Each dog was allowed to stand quietly in a Pavlov harness for $20-30$ min before beginning an experiment.

Experimental design. Each experiment consisted of a 120-min basal period (0-120 min), a 90-min hyperglycemic control period (period 1; 120-210 $\mathrm{min}$ ), and a 240-min experimental period (period 2; 210-450 min) (Fig. 1). In all experiments, a constant infusion of indocyanine green dye $\left(0.1 \mathrm{mg} \cdot \mathrm{m}^{-2} \cdot \mathrm{min}^{-1}\right)$ and a primed $(40 \mu \mathrm{Ci})$, continuous $(0.60 \mu \mathrm{Ci} / \mathrm{min})$ infusion of HPLC-purified $\mathrm{D}-\left[3-{ }^{3} \mathrm{H}\right]$-glucose were initiated at $0 \mathrm{~min}$. In addition, a constant peripheral infusion of PAH $\left(1.7 \mu \mathrm{mol} \cdot \mathrm{kg}^{-1} \cdot \mathrm{min}^{-1}\right)$ was started at $0 \mathrm{~min}$ and was continued throughout the study unless indicated below. At $120 \mathrm{~min}$, a constant infusion of somatostatin $\left(0.8 \mu \mathrm{g} \cdot \mathrm{kg}^{-1} \cdot \mathrm{min}^{-1}\right)$ was begun to suppress endogenous insulin and glucagon secretion, and constant intraportal infusions of insulin $\left(1.8 \mathrm{pmol} \cdot \mathrm{kg}^{-1} \cdot \mathrm{min}^{-1}\right)$ and glucagon $(0.65 \mathrm{ng} \cdot$ $\mathrm{kg}^{-1} \cdot \min ^{-1}$ ) were established to maintain basal levels of both hormones. In addition, a peripheral glucose infusion was started to produce hyperglycemia (arterial plasma levels of $\sim 180 \mathrm{mg} / \mathrm{dl}$ ). The peripheral glucose infusate was spiked with HPLC-purified D- $\left[3-{ }^{3} \mathrm{H}\right]-$ glucose to a specific activity that was estimated to be similar to the plasma glucose specific activity at the end of the basal period (based on historical controls). During period 1 (120-210 min) the constant tracer infusion that was initiated at 0 min was reduced by $50 \%$ in all groups to compensate for the reduction in hepatic glucose production that occurs as a result of hyperglycemia $(8,22)$. This tracer infusion was completely shut off in experiments in which hyperinsulinemia was created during period 2 (i.e., hyperinsulinemic, hyperglycemic [INS] and combined hyperinsulinemia and portal glucose infusion [INSPo] groups, see below). In the control protocol hyperglycemia was maintained in the presence of basal levels of insulin for an additional $240 \mathrm{~min}$ (210-450 min, hyperglycemic control group [CON], $n=6$ ). Three additional experimental protocols were carried out. The first evaluated the effect of a selective induction of the portal signal (portal glucose infusion group [Po], $n=6$ ). Basal insulin levels were maintained, but a constant intraportal glucose $(19.6 \mu \mathrm{mol}$. $\mathrm{kg}^{-1} \cdot \mathrm{min}^{-1}$ )/PAH infusion (PAH mixed with $20 \%$ dextrose in such a way that the PAH infusion rate was $1.7 \mu \mathrm{mol} \cdot \mathrm{kg}^{-1} \cdot \mathrm{min}^{-1}$ ) was initiated at $210 \mathrm{~min}$ and the peripheral glucose infusion was reduced to maintain comparable hyperglycemia at the liver to that in CON. The peripheral PAH infusion was discontinued at $210 \mathrm{~min}$. The portal glu-

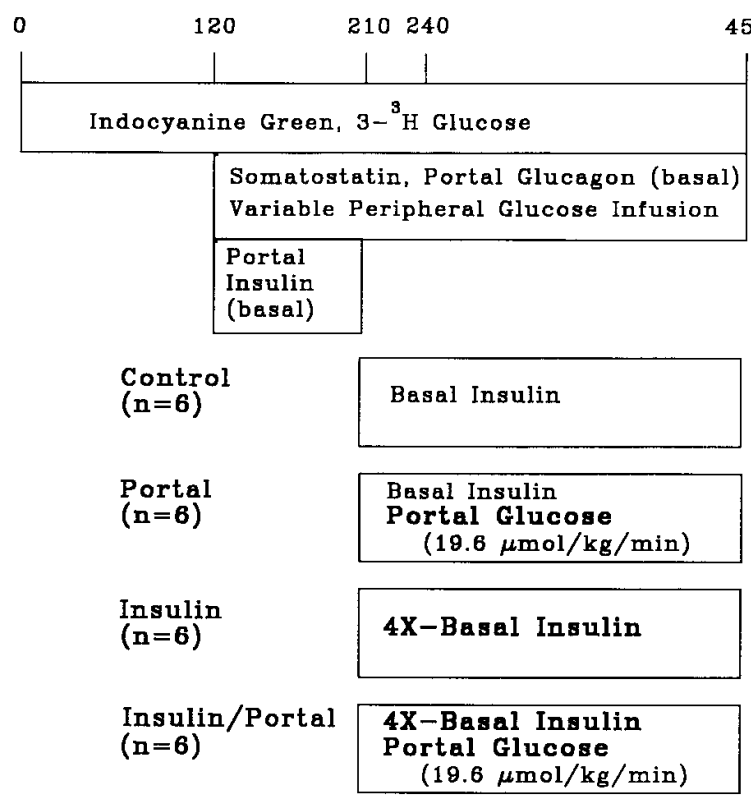

Figure 1. Experimental design for the control, portal, insulin, and insulin/portal protocols (CON, Po, INS, and INSPo, respectively, in text). 
cose infusate also contained $\mathrm{D}-\left[3-{ }^{3} \mathrm{H}\right]$-glucose to a specific activity that was equivalent to that of the peripheral glucose infusate. In the second protocol the effect of a selective rise in insulin was evaluated (INS, $n=6$ ). A fourfold rise in insulin was created (intraportal infusion of $7.2 \mathrm{pmol} \cdot \mathrm{kg}^{-1} \cdot \mathrm{min}^{-1}$ ) at $210 \mathrm{~min}$ and hyperglycemia at the liver was maintained via adjustments in the peripheral glucose infusion rate. In the third protocol the combined effect of insulin and the portal signal was evaluated (INSPo, $n=6$ ). A fourfold rise in insulin was brought about at $210 \mathrm{~min}$ in combination with an intraportal glucose/PAH infusion at the rate noted earlier. Hyperglycemia at the liver was again maintained via the peripheral glucose infusion. The peripheral PAH infusion was discontinued at $210 \mathrm{~min}$.

In separate experiments ( $n=6 /$ group) the protocols used for CON, Po, and INS were followed exactly as described above but were terminated at $240 \mathrm{~min}$ (i.e., $30 \mathrm{~min}$ into the experimental period).

Femoral artery, portal vein, and hepatic vein blood samples were taken every 15 min during the final $30 \mathrm{~min}$ of the basal period (90-120 $\mathrm{min}$ ) and period 1 (180-210 $\mathrm{min}$ ), giving three estimates of hepatic substrate and tracer balance in each period. During period 2 (210-450 min) blood samples were taken at 15-min intervals for the first $60 \mathrm{~min}$ and every $30 \mathrm{~min}$ during the final $180 \mathrm{~min}$. Arterial blood samples were also taken every 5-10 min throughout periods 1 and 2 to monitor the glucose level. The total volume of blood withdrawn did not exceed $20 \%$ of the animal's blood volume, and two volumes of normal saline were infused for each volume of blood withdrawn. The methods for collection and processing of blood samples have been described previously (19). The arterial and portal vein blood samples were taken simultaneously, and hepatic vein samples were collected $\sim 30$ s later to compensate for transit time of glucose through the liver (23).

After completion of each experiment, the animal was killed with an overdose of pentobarbital or with Beuthanasia-D, and a tissue sample from each of the seven liver lobes was rapidly frozen with clamps kept in liquid nitrogen (entire procedure required $<4 \mathrm{~min}$ ). The tissue was stored at $-70^{\circ} \mathrm{C}$ for later analysis of glycogen and glycogen synthase. Liver glycogen and glycogen synthase measurements were not significantly different among the lobes of a given animal.

Analytical procedures. Six determinations of the glucose concentration were made on each plasma sample using the glucose-oxidase method (24) in a glucose analyzer (Beckman Instruments, Inc., Fullerton, CA). Plasma glucose radioactivity was determined by liquid scintillation counting after deproteinization and evaporation to remove ${ }^{3} \mathrm{H}_{2} \mathrm{O}$. Blood concentrations of glucose (quadruplicate) and lactate (duplicate) were determined on perchloric acid extracts using an autoanalyzer (Technicon Instruments Corp., Tarrytown, NY) according to the method of Lloyd et al. (25). PAH concentrations were determined in triplicate on perchloric acid extracts of blood according to the method of Brun (26). The immunoreactive glucagon concentration in plasma samples to which $500 \mathrm{KIU} / \mathrm{ml}$ Trasylol (FBA Pharmaceuticals, New York) had been added was determined with Unger's $30 \mathrm{~K}$ antiserum (27), with an interassay coefficient of variation (CV) of $14 \%$. Immunoreactive insulin was measured as described previously (28), with an interassay CV of $11 \%$. Liver glycogen concentration was determined according to the method of Chan and Exton (29). Liver glycogen synthase was determined using the method described by Nuttall and Gannon (30). Indocyanine green was used to estimate hepatic blood flow according to the method of Leevy et al. (31). Doppler-determined hepatic blood flow was obtained using an ultrasonic, range-gated, pulsed Doppler flow meter designed by Hartley et al. (21).

Calculations and data analysis. Hepatic blood flow was estimated using both indocyanine green dye and Doppler flow probes as described previously $(32,33)$. These two independent techniques yielded similar values (see Results), and Doppler-determined hepatic blood flow was used in data calculation. The distribution of hepatic blood flow obtained from Doppler measurements was $80 \%$ in the portal vein and $20 \%$ in the hepatic artery during the control period; and $78 \%$ in the portal vein and $22 \%$ in the hepatic artery during periods 1 and 2. These data are consistent with previous work that demonstrated that somatostatin, at the dose used, does not significantly affect hepatic blood flow in the dog $(10,13,32,33)$.

When glucose is infused into the slow, laminar flow of the portal venous circulation, mixing of the blood and glucose can be problematic. PAH, a substance not extracted by the liver (verified by using the peripheral PAH infusion) or erythrocytes, was mixed with the intraportal glucose infusate; and the recovery of PAH across the liver was measured as described previously (33). Mixing in the hepatic vein was assessed by comparing the PAH infusion rate with the difference between the rate of PAH exiting the liver and the rate of PAH entering the splanchnic bed through the arterial system:

$$
\left([\mathrm{PAH}]_{\mathrm{A}}-[\mathrm{PAH}]_{\mathrm{H}}\right) \times \mathrm{HBF} ;
$$

where $A$ and $H$ represent femoral artery and hepatic vein, respectively, and $H B F$ represents hepatic blood flow. Mixing in the portal vein was assessed in a similar fashion:

$\left([\mathrm{PAH}]_{\mathrm{A}}-[\mathrm{PAH}]_{\mathrm{P}}\right) \times \mathrm{PBF} ;$

where $P$ represents the portal vein blood concentration, and $P B F$ represents portal blood flow. The ratio between the recovery of intraportally infused $\mathrm{PAH}$ and the actual intraportal $\mathrm{PAH}$ infusion rate was calculated and used as an index of mixing of the intraportal glucose infusate with the blood entering and exiting the liver. Because of the magnitude of the $\mathrm{CV}$ of the method for assessing PAH balance, samples were considered statistically unmixed $(>95 \%$ confidence

Table I. Assessment of Mixing Based on the Ratio of Portal or Hepatic PAH Balance to the PAH infusion Rate in 42-h-fasted, Conscious Dogs during the Experimental Period of the Portal and Insulin/Portal Protocols

\begin{tabular}{|c|c|c|}
\hline & Portal & Insulin/Portal \\
\hline \multicolumn{3}{|c|}{$\begin{array}{l}\text { Ratio of portal PAH balance } \\
\text { to the PAH infusion rate (min) }\end{array}$} \\
\hline 225 & $1.25 \pm 0.29$ & $0.96 \pm 0.14$ \\
\hline 240 & $1.08 \pm 0.24$ & $0.95 \pm 0.11$ \\
\hline 255 & $1.12 \pm 0.19$ & $1.04 \pm 0.13$ \\
\hline 270 & $1.13 \pm 0.13$ & $1.04 \pm 0.18$ \\
\hline 300 & $1.03 \pm 0.12$ & $0.98 \pm 0.17$ \\
\hline 330 & $1.13 \pm 0.13$ & $1.02 \pm 0.10$ \\
\hline 360 & $1.29 \pm 0.19$ & $1.05 \pm 0.08$ \\
\hline 390 & $1.03 \pm 0.14$ & $0.95 \pm 0.09$ \\
\hline 420 & $1.26 \pm 0.07$ & $1.07 \pm 0.12$ \\
\hline 450 & $1.12 \pm 0.11$ & $0.98 \pm 0.13$ \\
\hline \multicolumn{3}{|c|}{$\begin{array}{l}\text { Ratio of hepatic PAH balance } \\
\text { to the PAH infusion rate (min) }\end{array}$} \\
\hline 225 & $1.13 \pm 0.10$ & $1.01 \pm 0.08$ \\
\hline 240 & $1.01 \pm 0.09$ & $0.99 \pm 0.09$ \\
\hline 255 & $1.03 \pm 0.14$ & $1.02 \pm 0.11$ \\
\hline 270 & $0.99 \pm 0.12$ & $1.05 \pm 0.14$ \\
\hline 300 & $0.95 \pm 0.10$ & $1.01 \pm 0.09$ \\
\hline 330 & $1.04 \pm 0.09$ & $0.99 \pm 0.08$ \\
\hline 360 & $1.10 \pm 0.12$ & $1.03 \pm 0.09$ \\
\hline 390 & $1.01 \pm 0.13$ & $0.98 \pm 0.13$ \\
\hline 420 & $1.09 \pm 0.10$ & $1.05 \pm 0.12$ \\
\hline 450 & $1.04 \pm 0.13$ & $1.01 \pm 0.13$ \\
\hline
\end{tabular}

Values are mean \pm SE for six animals in each group. A ratio of 1.00 would represent perfect mixing of the portal glucose infusate in either the portal or hepatic veins. 
that mixing did not occur) if hepatic or portal vein recovery of intraportally infused $\mathrm{PAH}$ was $40 \%$ greater or less than the actual amount of PAH infused (33).

In Table I, mixing data for the experimental period are provided for the portal and insulin/portal groups (i.e., the two groups in which portal glucose infusion was used). Seven animals were studied in each of these groups and one animal from each group was rejected because of poor mixing during the experimental period. Poor mixing was defined as a ratio $>1.4$ or $<0.6$ at three or more of the time points in the experimental period (measurements were made at 10 time points). In the 12 studies included in the data base for the portal and insulin/ portal groups, the infusate failed to mix with the blood $<10 \%$ of the time (i.e., average of less than one sample per study). More importantly, when mixing errors did occur, they were random. As a result, no data points were excluded from the data base when the experiment as a whole was included.

The hepatic substrate load was calculated directly as:

$\mathrm{LOAD}_{\text {in (D) }}=\left(\left[\mathrm{C}_{\mathrm{A}} \times \mathrm{ABF}\right]+\left[\mathrm{C}_{\mathrm{P}} \times \mathrm{PBF}\right]\right) ;$

where $C$ represents the substrate concentration in blood, and $A B F$ represents the hepatic artery blood flow. In glucose balance calculations, plasma glucose values were converted to whole-blood values by using a correction factor (CF) obtained by averaging the ratio of the whole-blood glucose value to the plasma glucose value at each time point throughout the study. A separate $\mathrm{CF}$ was established for each sampling site in each dog. Mean CFs were $0.71 \pm 0.01$ for the artery, $0.71 \pm 0.01$ (control and experimental period when a peripheral glucose infusion was used) and $0.69 \pm 0.01$ (experimental period when portal glucose infusion was present) for the portal vein, and $0.70 \pm$ 0.01 for the hepatic vein. For the artery and hepatic vein, one CF was used for the entire study, since the ratios between whole blood and plasma glucose were found to be the same in the control and experimental periods. Calculations performed with plasma glucose values converted to blood glucose values gave almost identical results to those performed with blood glucose values per se, but the variance was reduced because of the accuracy of plasma arterio-venous differences, which do not require a deproteinization step. The use of whole blood glucose ensures accurate hepatic balance measurements regardless of the characteristics of glucose entry into the erythrocyte. To circumvent any potential errors arising from either incomplete mixing of glucose in the circulation during intraportal glucose infusion or lack of precise measurements of the distribution of hepatic blood flow, a second, indirect method of calculating the hepatic glucose load was used:

$\mathrm{LOAD}_{\text {in (I) }}=\left(\mathrm{G}_{\mathrm{A}} \times \mathrm{HBF}\right)+\mathrm{GIR}_{\mathrm{Po}}-\mathrm{GUG}$;

where $G$ represents the blood glucose concentration, $G I R_{P_{\mathrm{O}}}$ represents the glucose infusion rate into the portal vein, and $G U G$ represents the uptake of glucose by the gastrointestinal tract. GUG was calculated based on the previously described relationship between the arterial blood glucose concentration and GUG (33).

The load of a substrate exiting the liver was calculated as:

$\mathrm{LOAD}_{\text {out }}=\mathrm{C}_{\mathrm{H}} \times \mathrm{HBF}$.

Net hepatic glucose balance (NHGB) was calculated by two separate methods as described previously $(10,33)$. In the first, referred to as the direct calculation:

$\mathrm{NHGB}_{\mathrm{D}}=\mathrm{LOAD}_{\text {out }}-\mathrm{LOAD}_{\text {in (D) }}$.

In the second, referred to as the indirect calculation:

$\mathrm{NHGB}_{\mathrm{I}}=\mathrm{LOAD}_{\text {out }}-\mathrm{LOAD}_{\text {in (I) }}$.

In these calculations, a positive value indicates net output. In the text, hepatic glucose load and NHGB using the indirect calculation are provided. However, it should be noted that the estimate of NHGB was similar regardless of which method was used in calculations. For other substrates, the direct calculation was used to calculate net balance. The net balance of glucose equivalents across the liver was calculated as the sum of the balances of $\mathrm{NHGB}_{\mathrm{I}}$ and lactate, once the latter was converted to glucose equivalents.

Rates of glucose production ( $\mathrm{Ra}$ ) and utilization ( $\mathrm{Rd})$ were assessed by isotope dilution during the basal period (34). During periods 1 and $2 \mathrm{Ra}$ and $\mathrm{Rd}$ were estimated using a modification of the Steele equation as described previously (34-36). During the experimental periods endogenous glucose production (Endo Ra) was estimated by subtracting the rate of exogenous glucose infusion from the total glucose Ra. Since the liver can simultaneously remove and produce glucose, the absolute rate of glucose uptake (hepatic glucose uptake or HGU) was calculated in two ways. In the first, HGU was calculated as the difference between endogenous glucose Ra and NHGB. In the second, the balance of $\mathrm{D}-\left[3{ }^{3} \mathrm{H}\right]$-glucose across the liver was used to calculate HGU exactly as described for unlabeled glucose, except that plasma concentration and plasma flow measurements were used. These calculations assume that there is minimal release of tracer glucose by the liver. Similar to unlabeled glucose, tracer balance measurements were unaffected by the means of calculation (i.e., direct versus indirect).

All data are presented as means \pm SEM. Statistical comparisons were made using repeated measures ANOVA. Statistical significance was accepted at $P<0.05$.

\section{Results}

Plasma insulin, glucagon, glucose, arterial-portal glucose gradient, and hepatic blood flow. Plasma insulin levels in the artery $(\sim 45 \mathrm{pM})$ and portal vein $(\sim 151 \mathrm{pM})$ were similar among groups during the basal period (80-120 min; Fig. 2) and during period 1 (180-210 min; Fig. 2). In period 2 (210-450 min; Fig. 2) these values were unchanged in $\mathrm{CON}$ and Po and were elevated approximately fourfold in both INS and INSPo. Arterial plasma glucagon levels were similar among groups and did not change throughout the study (Table II). Arterial and portal glucose levels and the arterial-portal plasma glucose gradient were similar among groups during the basal period and period 1 (Table III). During period 2 arterial and portal glucose levels were similar in the CON and INS groups (Table III). In Po and INSPo during period 2 arterial glucose levels were $\sim 5 \%$ lower and portal glucose levels were $\sim 8 \%$ higher than CON and INS due to the presence of the intraportal glucose infusion. Thus, the intraportal glucose infusion produced a negative arterial-portal plasma glucose gradient of $\sim-1.19 \mathrm{mM}$ and thereby presented the liver with the portal signal.

Doppler-determined hepatic blood flow was 31.6 \pm 2.3 , $32.9 \pm 3.6,32.6 \pm 2.9$, and $31.3 \pm 4.1 \mathrm{ml} \cdot \mathrm{kg}^{-1} \cdot \mathrm{min}^{-1}$ during the basal period in CON, INS, Po, and INSPo, respectively. During the same period indocyanine green estimated hepatic blood flow was $33.9 \pm 5.2,31.4 \pm 4.5,33.7 \pm 5.3$, and $29.9 \pm 4.8$ $\mathrm{ml} \cdot \mathrm{kg}^{-1} \cdot \mathrm{min}^{-1}$ in CON, INS, Po, and INSPo, respectively. Doppler-determined hepatic blood flow was similar between

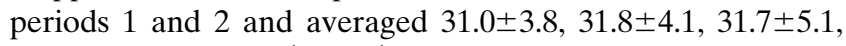
and $30.6 \pm 4.0 \mathrm{ml} \cdot \mathrm{kg}^{-1} \cdot \mathrm{min}^{-1}$ in CON, INS, Po, and INSPo, respectively. Average rates of indocyanine green estimated hepatic blood flow were $31.9 \pm 4.9,30.5 \pm 5.3,31.3 \pm 4.6$, and $29.7 \pm 5.5 \mathrm{ml} \cdot \mathrm{kg}^{-1} \cdot \mathrm{min}^{-1}$ during the same time period.

Hepatic glucose load and total glucose infusion rate. The hepatic glucose load was similar both within and among groups throughout the study (Fig. 3). During the control period the hepatic glucose load averaged $123 \mu \mathrm{mol} \cdot \mathrm{kg}^{-1} \cdot \mathrm{min}^{-1}$ and it was increased to $\sim 278 \mu \mathrm{mol} \cdot \mathrm{kg}^{-1} \cdot \mathrm{min}^{-1}$ during periods 


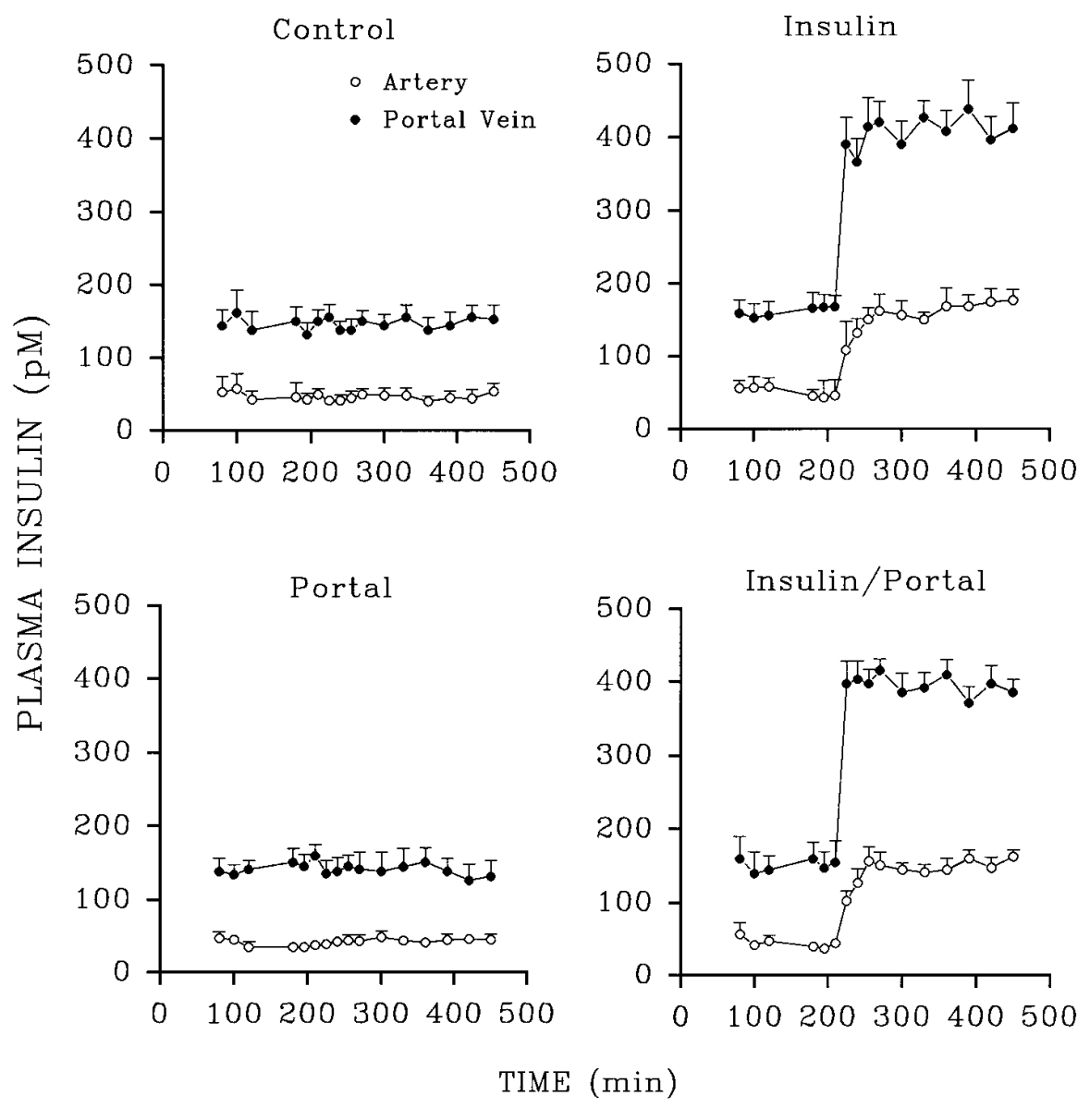

Figure 2. Plasma insulin levels in the femoral artery and portal vein in 42 -hfasted, conscious dogs during the control, insulin, portal, and insulin/portal protocols $(n=6$ for each). Data are means \pm SEM.
1 and 2 (Fig. 3). The glucose infusion rate during period 1 was similar among groups $\left(20.8 \mu \mathrm{mol} \cdot \mathrm{kg}^{-1} \cdot \mathrm{min}^{-1}\right.$; Fig. 3) and did not change significantly in either $\mathrm{CON}$ or Po during period 2. In contrast, the glucose infusion rate reached maximum values

Table II. Arterial Plasma Glucagon Levels (ng/liter) in 42-hfasted, Conscious Dogs during the Basal Period (80-120 min) and Periods 1 (180-210 min) and 2 (210-450 $\mathrm{min})$

\begin{tabular}{rlllc}
\hline Time & Control & Insulin & Portal & Insulin/Portal \\
\hline 80 & $50 \pm 12$ & $47 \pm 7$ & $41 \pm 7$ & $56 \pm 4$ \\
100 & $53 \pm 12$ & $45 \pm 7$ & $42 \pm 9$ & $54 \pm 5$ \\
120 & $53 \pm 10$ & $47 \pm 11$ & $45 \pm 9$ & $55 \pm 5$ \\
180 & $55 \pm 6$ & $43 \pm 6$ & $48 \pm 7$ & $58 \pm 4$ \\
195 & $55 \pm 6$ & $46 \pm 3$ & $50 \pm 7$ & $56 \pm 4$ \\
210 & $55 \pm 6$ & $47 \pm 3$ & $48 \pm 6$ & $57 \pm 6$ \\
225 & $53 \pm 7$ & $49 \pm 5$ & $44 \pm 5$ & $53 \pm 5$ \\
240 & $52 \pm 8$ & $51 \pm 5$ & $46 \pm 9$ & $58 \pm 5$ \\
255 & $53 \pm 8$ & $47 \pm 4$ & $46 \pm 7$ & $56 \pm 5$ \\
270 & $60 \pm 10$ & $48 \pm 3$ & $48 \pm 7$ & $53 \pm 5$ \\
300 & $54 \pm 8$ & $49 \pm 3$ & $46 \pm 8$ & $52 \pm 5$ \\
330 & $53 \pm 8$ & $48 \pm 2$ & $44 \pm 6$ & $51 \pm 5$ \\
360 & $49 \pm 9$ & $52 \pm 5$ & $48 \pm 7$ & $52 \pm 3$ \\
390 & $47 \pm 8$ & $51 \pm 5$ & $47 \pm 6$ & $53 \pm 3$ \\
420 & $47 \pm 8$ & $50 \pm 2$ & $43 \pm 7$ & $49 \pm 4$ \\
450 & $49 \pm 6$ & $48 \pm 1$ & $45 \pm 6$ & $49 \pm 4$ \\
& & & & \\
\hline
\end{tabular}

Values are means \pm SEM for six animals in each group. No significant differences were observed among groups. of $57.2 \pm 9.3 \mu \mathrm{mol} \cdot \mathrm{kg}^{-1} \cdot \mathrm{min}^{-1}$ in INS and $60.5 \pm 9.3 \mu \mathrm{mol}$. $\mathrm{kg}^{-1} \cdot \mathrm{min}^{-1}$ in INSPo (both $P<0.05$ vs. CON and Po) by the end of period 2 (i.e., 450-min time point; Fig. 3).

Net hepatic glucose balance, plasma glucose specific activity (SA), and tracer-estimated glucose production (Endo $R a$ ). During the basal period net hepatic glucose output averaged $8.1 \pm 1.8,8.9 \pm 0.6,6.5 \pm 2.0$, and $7.1 \pm 1.0 \mu \mathrm{mol} \cdot \mathrm{kg}^{-1} \cdot \mathrm{min}^{-1}$ in CON, INS, Po, and INSPo groups, respectively (Fig. 4). Net hepatic glucose output was reduced during period 1 to similar average values of $0.5 \pm 3.1,1.6 \pm 2.7,-0.7 \pm 1.9$, and $-1.7 \pm 1.8$ $\mu \mathrm{mol} \cdot \mathrm{kg}^{-1} \cdot \mathrm{min}^{-1}$ in CON, INS, Po, and INSPo groups, respectively (Fig. 4, negative value denotes uptake). In CON, net hepatic glucose balance was similar during periods 1 and 2 (range $=1.0$ to $\left.-2.6 \mu \mathrm{mol} \cdot \mathrm{kg}^{-1} \cdot \mathrm{min}^{-1}\right)$. In Po, net hepatic glucose balance during period 2 rapidly switched to uptake and was at a maximum $\left(-13.0 \pm 3.7 \mu \mathrm{mol} \cdot \mathrm{kg}^{-1} \cdot \mathrm{min}^{-1}\right)$ at $225 \mathrm{~min}$ (15 min into period 2; $P<0.05$ vs. CON and INS). In contrast, net hepatic glucose balance was $-3.8 \pm 3.3 \mu \mathrm{mol} \cdot \mathrm{kg}^{-1} \cdot \mathrm{min}^{-1}$ at $225 \mathrm{~min}$ in INS and did not reach a maximum $\left(-16 \mu \mathrm{mol} \cdot \mathrm{kg}^{-1}\right.$. $\min ^{-1}$ ) until $300 \mathrm{~min}$ (90 min into period 2; Fig. 4). In INSPo net hepatic glucose balance was $-15.4 \pm 2.5 \mu \mathrm{mol} \cdot \mathrm{kg}^{-1} \cdot \mathrm{min}^{-1}$ at $225 \mathrm{~min}(P<0.05$ vs. INS and $\mathrm{CON})$ and $-23.6 \pm 3.5$ $\mu \mathrm{mol} \cdot \mathrm{kg}^{-1} \cdot \mathrm{min}^{-1}$ by $270 \mathrm{~min}(P<0.05 \mathrm{vs}$. other groups $)$.

The net contribution of the liver to the removal of infused glucose is presented in Table IV. In Po this contribution was between 60 and $89 \%$ throughout period 2 . In INS the net contribution of the liver to the removal of infused glucose was $18 \%$ at $15 \mathrm{~min}$ of period 2 and increased to values ranging from 24 to $43 \%$ thereafter ( $P<0.05$ vs. Po and INSPo). In INSPo the liver's contribution was highest during the first 30 
Table III. Arterial and Portal Plasma Glucose Concentration and the Arterial-Portal Plasma Glucose Gradient during the Basal Period and Periods 1 (180-210 min) and 2 (210-450 min) in 42-h-fasted, Conscious Dogs

\begin{tabular}{lccc}
\hline & Basal period & Period 1 & Period 2 \\
\hline Arterial plasma glucose $(\mathrm{mM})$ & & & \\
Control & $5.40 \pm 0.30$ & $13.22 \pm 0.61^{*}$ & $13.21 \pm 0.64^{*}$ \\
Insulin & $5.63 \pm 0.33$ & $13.07 \pm 0.75^{*}$ & $12.99 \pm 0.58^{*}$ \\
Portal & $5.79 \pm 0.41$ & $12.60 \pm 0.56^{*}$ & $11.97 \pm 0.51^{*}$ \\
Insulin/Portal & $5.61 \pm 0.25$ & $13.07 \pm 0.46^{*}$ & $12.52 \pm 0.54^{*}$ \\
& & & \\
Portal plasma glucose $(\mathrm{mM})$ & & \\
Control & $5.17 \pm 0.33$ & $12.82 \pm 0.57^{*}$ & $12.83 \pm 0.64^{*}$ \\
Insulin & $5.48 \pm 0.39$ & $12.68 \pm 0.69^{*}$ & $12.69 \pm 0.71^{*}$ \\
Portal & $5.55 \pm 0.20$ & $12.22 \pm 0.58^{*}$ & $13.28 \pm 0.69^{*}$ \\
Insulin/Portal & $5.40 \pm 0.21$ & $12.75 \pm 0.81^{*}$ & $13.60 \pm 0.75^{*}$ \\
& & & \\
Arterial-portal plasma glucose gradient & $(\mathrm{mM})$ & & \\
Control & $0.23 \pm 0.04$ & $0.39 \pm 0.08^{*}$ & $0.40 \pm 0.07^{*}$ \\
Insulin & $0.15 \pm 0.03$ & $0.38 \pm 0.06^{*}$ & $0.31 \pm 0.07^{*}$ \\
Portal & $0.24 \pm 0.05$ & $0.28 \pm 0.04$ & $-1.30 \pm 0.19^{*}$ \\
Insulin/Portal & $0.22 \pm 0.05$ & $0.30 \pm 0.06$ & $-1.08 \pm 0.16^{*}$ \\
& & & \\
\hline
\end{tabular}

Values are mean \pm SEM for six animals in each group. Basal period represents the average of three values taken between 80 and $120 \mathrm{~min}$. Period 1 represents the average of three values taken between 180 and 210 min. Period 2 represents the average of 10 values taken between 120 and $450 \mathrm{~min}$. A negative arterial portal glucose gradient reflects the presence of intraportal glucose infusion or the portal signal. * Significantly $(P<0.05)$ different from basal period.

min of period $2(70-79 \%)$ and decreased thereafter to values ranging from 37 to $61 \%$.

In Fig. 5 plasma glucose SA is presented for the basal, hyperglycemic control, and experimental periods. Inclusion of the spiked exogenous glucose infusion minimized changes in the glucose SA. In general, the glucose SA rose slightly but not significantly $(P>0.05)$ from the basal period to period 1 in all groups. There was a small additional nonsignificant $(P>0.05)$ rise in the glucose SA during period 2 in INS and INSPo.

Endo Ra was similar among groups during the basal period and period 1 (Table V). In both CON and Po, Endo Ra was also similar between periods 1 and 2 (Table V), thus the presence of the portal signal did not result in any further suppression of hepatic glucose production. In contrast, the presence of hyperinsulinemia produced essentially complete suppression of Endo Ra during period 2 in both INS and INSPo (Table V). HGU was only slightly increased by hyperglycemia alone (basal compared with period 1$)$ but was significantly $(P<0.05)$ increased when hyperglycemia was combined with either hyperinsulinemia or the portal signal (Table V). The combination of hyperinsulinemia and the portal signal did not produce an additive increase in HGU (Table V).

Net hepatic lactate balance and the net balance of glucose equivalents across the liver. During the basal period, rates of net hepatic lactate uptake were $-7.9 \pm 1.6,-9.4 \pm 0.8$, $-6.8 \pm 2.2$, and $-6.9 \pm 2.9 \mu \mathrm{mol} \cdot \mathrm{kg}^{-1} \cdot \mathrm{min}^{-1}$ in CON, INS, Po, and INSPo, respectively (Fig. 6). Net hepatic lactate uptake was reduced by hyperglycemia in all four groups (Fig. 6). In CON lactate balance across the liver was essentially zero during period 2. Peak rates of net hepatic lactate output were


Figure 3. Hepatic glucose load (top) and total glucose infusion rate (bottom) in 42-h-fasted, conscious dogs during the control, insulin, portal, and insulin/portal protocols ( $n=6$ for each). Data are means \pm SEM.

achieved $45 \mathrm{~min}$ into period 2 in both INS $(12.2 \pm 4.9 \mu \mathrm{mol} \cdot$ $\left.\mathrm{kg}^{-1} \cdot \mathrm{min}^{-1}\right)$ and INSPo (14.3 $\pm 3.4 \mu \mathrm{mol} \cdot \mathrm{kg}^{-1} \cdot \mathrm{min}^{-1}$; Fig. 6). In contrast, peak rates of net hepatic lactate output (12.2 \pm 4.1 $\left.\mu \mathrm{mol} \cdot \mathrm{kg}^{-1} \cdot \mathrm{min}^{-1}\right)$ were not observed in Po until $90 \mathrm{~min}$ into period 2 (Fig. 6).

The net balance of glucose equivalents across the liver reached a maximum of $-10.7 \pm 1.9 \mu \mathrm{mol} \cdot \mathrm{kg}^{-1} \cdot \mathrm{min}^{-1}$ after only $15 \mathrm{~min}$ of period 2 in Po, whereas in both INS $(-16.4 \pm 1.0$ $\left.\mu \mathrm{mol} \cdot \mathrm{kg}^{-1} \cdot \mathrm{min}^{-1}\right)$ and INSPo $\left(-19.3 \pm 1.1 \mu \mathrm{mol} \cdot \mathrm{kg}^{-1} \cdot \mathrm{min}^{-1}\right)$ maximal rates were not observed until $60-120 \mathrm{~min}$ of period 2 (Fig. 6).

Liver glycogen concentration and glycogen synthase activity. Terminal liver glycogen levels were significantly $(P<$ 0.05 ) increased in INS, Po, and INSPo compared with CON (Table VI). Terminal liver glycogen synthase activity was significantly $(P<0.05)$ increased in INS and INSPo only (Table $\mathrm{VI})$. The complementary relationship between the portal sig- 


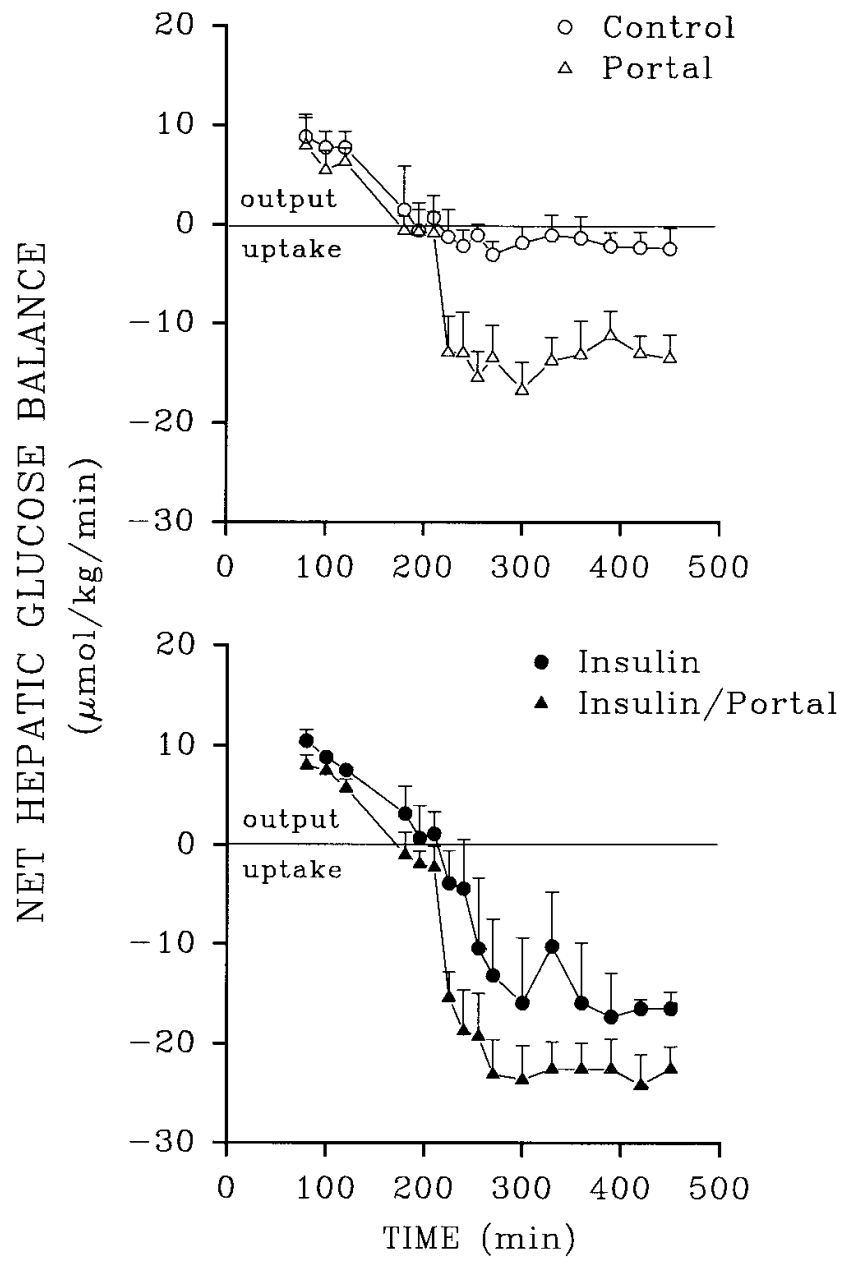

Figure 4. Net hepatic glucose balance in 42-h-fasted, conscious dogs during the control and portal protocols (top, $n=6$ for each) and during the insulin and insulin/portal protocols (bottom, $n=6$ for each). Data are means \pm SEM.

nal and insulin is illustrated by comparing the effect of the portal signal on liver glycogen and glycogen synthase activity in the presence (INSPo versus INS) and absence of hyperinsulinemia (Po versus CON). In the absence of hyperinsulinemia the portal signal resulted in an increment in liver glycogen of $44 \mu \mathrm{mol} / \mathrm{gram}$ and glycogen synthase of $2.1 \%$, whereas in the presence of hyperinsulinemia the portal signal produced increments of $50 \mu \mathrm{mol} / \mathrm{gram}$ and $2 \%$.

In Table VII the increment in liver glycogen concentration and glycogen synthase activity is presented after either 30 or 240 min of period 2 . In INS $\sim 10 \%$ of the total increment in liver glycogen occurred over the first $30 \mathrm{~min}$, whereas in Po $\sim 35 \%$ of the total increment occurred over this same time period. The increment in liver glycogen synthase activity was greater after $30 \mathrm{~min}$ in both INS and Po compared with the increment in synthase activity observed at $240 \mathrm{~min}$.

\section{Discussion}

The liver is an important site of glucose removal after a meal $(1,8,13,18,33,37,38)$. Several studies have demonstrated that the combination of hyperglycemia, hyperinsulinemia, and in-
Table IV. Percent Net Contribution of the Liver to the Removal of Glucose Infused during Periods 1 (180-120 min) and 2 (210-450 min) in 42-h-fasted, Conscious Dogs

\begin{tabular}{rcccc}
\hline Time & Control & Insulin & Portal & Insulin/Portal \\
\hline 80 & & & & \\
100 & & & & \\
120 & & & & \\
180 & 0 & 0 & 2.5 & 3.9 \\
195 & 3.2 & 0 & 3.2 & 7.8 \\
210 & 0 & 0 & 4.6 & 8.1 \\
225 & 6.4 & 18.0 & 69.4 & 70.0 \\
240 & 11.8 & 19.1 & 69.7 & 78.9 \\
255 & 5.2 & 41.3 & 85.1 & 61.4 \\
270 & 15.5 & 40.3 & 74.6 & 55.3 \\
300 & 9.8 & 43.3 & 89.4 & 50.0 \\
330 & 5.2 & 24.5 & 73.8 & 43.2 \\
360 & 6.7 & 33.3 & 70.6 & 38.3 \\
390 & 10.2 & 35.4 & 60.3 & 40.6 \\
420 & 10.4 & 30.0 & 68.0 & 41.5 \\
450 & 12.0 & 28.9 & 68.6 & 37.3 \\
& & & & \\
\hline
\end{tabular}

Values are average for six animals in each group. Percent contribution was calculated as NHGU divided by the total glucose infusion rate. Where net hepatic glucose balance was positive (i.e., net glucose output), the net contribution of the liver was taken as zero.

traportal glucose infusion (portal signal) can produce rates of NHGU that are comparable with rates observed after glucose ingestion $(32,39,40)$. This study sought to define the relative importance of these three variables to the time course of induction of NHGU and to determine their respective abilities to activate liver glycogen synthesis. The results demonstrate that under hyperglycemic conditions the portal signal, in contrast to insulin, produced a rapid ( $\sim 15 \mathrm{~min})$ stimulation of NHGU. Further, it produced activation of glycogen synthase

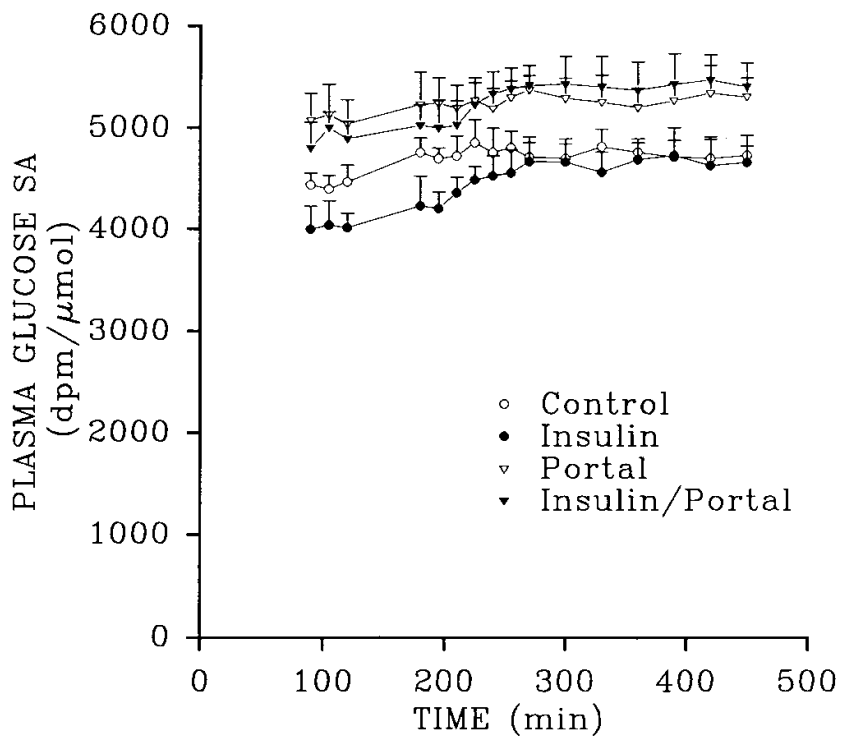

Figure 5. Plasma glucose SA in 42-h-fasted, conscious dogs during the control, insulin, portal, and insulin/portal protocols $(n=6$ for each). Data are means \pm SEM. 
Table V. Average Values for NHGB, Endo Ra, and HGU in Conscious, 42-h-fasted Dogs during the Final 30 min of the Basal Period (80-120 min) and Period 1 (180-210 min), and the Final 90 min of Period $2(360-450 \mathrm{~min})$

\begin{tabular}{llrcr}
\hline Experimental group & Period & \multicolumn{1}{c}{ NHGB } & Endo Ra & \multicolumn{1}{c}{ HGU } \\
\hline \multirow{4}{*}{ Control } & & \multicolumn{4}{c}{$\mu \mathrm{mol} / \mathrm{kg} / \mathrm{min}$} \\
& Basal & $8.1 \pm 1.8$ & $11.0 \pm 1.0$ & $2.9 \pm 1.6$ \\
& $\mathrm{P} 1$ & $0.5 \pm 3.1$ & $5.5 \pm 0.8$ & $5.0 \pm 1.9$ \\
& $\mathrm{P} 2$ & $-2.2 \pm 1.8$ & $5.0 \pm 0.7 *$ & $7.2 \pm 1.6$ \\
Insulin & Basal & $8.9 \pm 0.6$ & $12.1 \pm 0.9$ & $3.2 \pm 0.7$ \\
& P1 & $1.6 \pm 2.7$ & $5.8 \pm 1.2$ & $4.2 \pm 1.6$ \\
& P2 & $-16.6 \pm 3.2$ & $0.4 \pm 0.5$ & $17.0 \pm 2.0$ \\
Portal & Basal & $6.5 \pm 2.0$ & $9.6 \pm 1.0$ & $3.1 \pm 1.3$ \\
& P1 & $-0.7 \pm 1.9$ & $4.6 \pm 0.8$ & $5.3 \pm 1.4$ \\
& P2 & $-12.8 \pm 2.5$ & $5.3 \pm 0.6 *$ & $18.1 \pm 1.1$ \\
Insulin/Portal & Basal & $7.1 \pm 1.0$ & $10.0 \pm 0.8$ & $2.9 \pm 0.9$ \\
& P1 & $-1.7 \pm 1.8$ & $5.3 \pm 0.66$ & $7.0 \pm 1.3$ \\
& P2 & $-23.0 \pm 2.7$ & $0.5 \pm 0.4$ & $23.5 \pm 1.6$
\end{tabular}

Values are means \pm SEM for six animals in each group. P1 and P2 denote periods 1 and 2. A negative value for NHGB represents net uptake. HGU in the table is depicted as the difference between Endo Ra and NHGB. *Significantly $(P<0.05)$ different from insulin and insulin/ portal groups.

and glycogen accumulation in the absence of hyperinsulinemia. In contrast, a fourfold rise of insulin, brought about in the presence of hyperglycemia but in the absence of the portal signal, had a slowly $(\sim 90 \mathrm{~min})$ developing effect on liver glucose and glycogen metabolism. This was the case even though the rates of NHGU and liver glycogen accumulation that eventually developed were equivalent in the two groups. The combination of hyperinsulinemia, hyperglycemia, and the portal signal produced rates of NHGU and glycogen accumulation that were significantly greater than when hyperglycemia was combined with either the portal signal or hyperinsulinemia alone.

After a glucose- or high-carbohydrate-containing meal the liver is very rapidly presented with increased levels of glucose and insulin via the portal venous system. The liver's response to this increase in substrate and hormone delivery is to rapidly switch from net glucose production to net glucose removal (4, 19). However, several studies have demonstrated that insulin action on the liver develops slowly $(11,12)$. Further, combination of hyperinsulinemia and hyperglycemia in the absence of a portal signal fails to produce rates of NHGU that approach those observed after glucose ingestion $(13,32,40)$. Thus, the liver requires a signal that is associated with meal ingestion to activate NHGU rapidly and completely. The results from this study clearly demonstrate that portal glucose infusion generates such a signal. The portal signal is produced when the glucose level in the portal vein is elevated above that in the arterial system, a condition that is specific to meal ingestion. The rapid response of the liver to this signal suggests that it provides a way to tightly match glucose absorption (entry of glucose into the portal circulation) to liver glucose uptake and to thereby reduce or minimize perturbations of glucose in the systemic circulation.


Figure 6. Net hepatic lactate balance (top) and net balance of glucose equivalents across the liver (bottom) in 42-h-fasted, conscious dogs during the control, insulin, portal, and insulin/portal protocols $(n=6$ for each). The net balance of glucose equivalents is calculated as the sum of the net balances of glucose and lactate, the latter converted to glucose equivalents. Data are means \pm SEM.

For the same average concentration of glucose entering the liver, the portal vein glucose level is higher during intraportal glucose delivery than it is during a purely peripheral glucose infusion. Thus, it may seem that increased rates of NHGU after intraportal glucose delivery are simply the result of the larger load of glucose in the portal vein per se, and not a portal signal. However, two previous studies demonstrate that this is not the case $(10,33)$. Thus, when portal vein glucose levels were equated, rates of NHGU remained significantly higher during intraportal glucose infusion compared with peripheral glucose infusion. Our previous data clearly establish that increased rates of NHGU in response to intraportal glucose delivery are the result of a signal that is generated by the gradient of glucose between the portal vein and the arterial system (10, 33). The dramatic response of liver glucose uptake to the small $8 \%$ increase in the portal vein glucose concentration (when compared with the control and insulin groups) produced by the intraportal glucose infusion in the present study supports 
Table VI. Terminal Liver Glycogen Levels ( $\mu$ mol/gram) and Glycogen Synthase Activity (Percent Active Form) in 42-hfasted, Conscious Dogs

\begin{tabular}{lcc}
\hline Experimental group & Liver glycogen & Liver glycogen synthase \\
\hline Control & $175 \pm 16$ & $6.2 \pm 0.8$ \\
Insulin & $238 \pm 25^{*}$ & $12.0 \pm 1.4^{* \ddagger}$ \\
Portal & $219 \pm 16^{*}$ & $8.3 \pm 0.8$ \\
Insulin/Portal & $288 \pm 23^{* \ddagger}$ & $14.0 \pm 1.0^{* \ddagger}$
\end{tabular}

Values are means \pm SEM for six animals in each group. Values represent the average from seven liver lobes. No significant differences were evident between liver lobes in any of the groups. *Significantly $(P<0.05)$ different from control group value. ${ }^{*}$ Significantly $(P<0.05)$ different from portal group value.

our previous work, and confirms the importance of the gradient of glucose between the arterial and portal venous systems in regulating $\mathrm{NHGU}$.

In this study a fourfold rise in insulin, created in the presence of hyperglycemia but in the absence of the portal signal, produced rates of NHGU that were eventually similar to those seen with the portal signal. However, the time required to achieve this rate was significantly greater with insulin than with the portal signal. In addition, the response of the liver to hyperinsulinemia was different from the response of the liver to the portal signal. During period 1, hyperglycemia alone (i.e., without the portal signal) reduced hepatic glucose production (Endo Ra; Table IV) by $\sim 50 \%$ in all groups (average value of $10.7 \pm 0.9 \mu \mathrm{mol} \cdot \mathrm{kg}^{-1} \cdot \mathrm{min}^{-1}$ in the basal period to $5.3 \pm 0.8 \mu \mathrm{mol} \cdot$ $\mathrm{kg}^{-1} \cdot \min ^{-1}$ in period 1). Net hepatic glucose balance during period 1 was essentially zero, therefore hepatic glucose uptake

Table VII. Calculated Increment in Liver Glycogen ( $\mu$ mol) gram) and Glycogen Synthase (Percent Active Form) in 42-hfasted, Conscious Dogs after either 30 or 240 min of Hyperglycemia Alone (Control), Combined Hyperglycemia and Hyperinsulinemia (Insulin), Hyperglycemia in the Presence of the Portal Signal (Portal), or Combined Hyperglycemia and Hyperinsulinemia in the Presence of the Portal Signal (Insulin/Portal)

\begin{tabular}{lccccc}
\hline & \multicolumn{2}{c}{ Liver glycogen } & & \multicolumn{2}{c}{ Liver glycogen synthase } \\
\cline { 2 - 3 } \cline { 5 - 6 } Experimental group & $30 \mathrm{~min}$ & $240 \mathrm{~min}$ & & $30 \mathrm{~min}$ & $240 \mathrm{~min}$ \\
\hline Control & $1 \pm 2$ & $21 \pm 10$ & & $0.2 \pm 0.2$ & $0.7 \pm 0.4$ \\
Insulin & $8 \pm 3^{*}$ & $84 \pm 17^{*}$ & & $15.7 \pm 3.7^{*}$ & $6.5 \pm 1.2^{* *}$ \\
Portal & $22 \pm 9^{* *}$ & $65 \pm 16^{*}$ & & $9.8 \pm 2.7 *$ & $2.8 \pm 1.0$ \\
Insulin/Portal & & $134 \pm 17^{* *}$ & & & $8.5 \pm 1.3^{*}$
\end{tabular}

Values are means \pm SEM for six animals in each group and at each time point. Where missing values appear, no data are available. The increments in glycogen and glycogen synthase were calculated based on mean data obtained from a separate group of animals $(n=8)$ treated identically to those above but who were killed immediately after the hyperglycemic control period. Average values for liver glycogen and glycogen synthase in this group were $154 \pm 3 \mu \mathrm{mol} / \mathrm{gram}$ and $5.5 \pm 0.4 \%$, respectively. *Significantly $(P<0.05)$ different from control group. \#Significantly different $(P<0.05)$ from other groups at a similar time point. (calculated as the difference between hepatic glucose production and net hepatic glucose balance) was $\sim 5.4 \mu \mathrm{mol} \cdot$ $\mathrm{kg}^{-1} \cdot \mathrm{min}^{-1}$. The addition of hyperinsulinemia (INS group) resulted in a rate of NHGU of $\sim 17 \mu \mathrm{mol} \cdot \mathrm{kg}^{-1} \cdot \mathrm{min}^{-1}$ during the final $90 \mathrm{~min}$ of period 2 (Table III). This rate of NHGU was achieved through both an increase in hepatic glucose uptake and further suppression of hepatic glucose production. In contrast, the increase in NHGU that occurred in response to the portal signal was caused solely by an increase in hepatic glucose uptake. These data imply that the portal signal exerts its effect primarily via stimulation of uptake processes in the liver and that hyperinsulinemia can serve a complementary role to that of the portal signal through its ability to both suppress hepatic glucose production and stimulate hepatic glucose uptake.

Although we $(10,13,32,33,38)$ and others $(40,41)$ have demonstrated previously that the portal signal can increase NHGU, the fate of the extra glucose taken up by the liver in response to this signal was not directly measured. It is important to address this issue since glucose can have multiple fates within the liver (i.e., glycogen, carbon dioxide, glycolytic products, pentose phosphate cycle, and lipid). This study demonstrates that the portal signal, in the presence and absence of hyperinsulinemia, can produce both activation of liver glycogen synthase and significant glycogen accumulation. Thus, the portal signal appears to not only divert glucose that enters the portal vein into the liver, but to direct a significant portion $(\sim 75 \%)$ of it into glycogen. The remainder appears to primarily leave the liver as lactate.

In this study the net balance of glucose equivalents across the liver was determined based on the combination of glucose and lactate balances (the latter converted to glucose equivalents). This calculation allows one to estimate the net retention of glucose equivalents by the liver and can therefore provide an estimate of the glucose available for glycogen synthesis (assuming all of the glucose retained is converted to glycogen). This calculation does not include the potential contribution of gluconeogenic precursors that are extracted by the liver. Over the course of the 4-h experimental period the net retention of glucose by the liver was $\sim 9,62,46$, and $95 \mathrm{mmol}$ in the control, insulin, portal, and insulin/portal groups, respectively. Based on an average liver weight of 660 grams the amount of glycogen that could accumulate over this time period would be $13,95,70$, and $144 \mu \mathrm{mol} /$ gram liver in the four groups, respectively. These values are similar to the measured increments in liver glycogen found in Table V. Taken together these results suggest that most of the glucose equivalents retained by the liver were diverted into glycogen and were not oxidized or stored as fat.

During the first $60 \mathrm{~min}$ of period $2(210-450 \mathrm{~min})$ there was a positive relationship between $\mathrm{NHGU}$ and net hepatic lactate production. Thus, net hepatic lactate production was established earlier when the portal signal was present and was largest in the insulin/portal group. This relationship suggests that insulin and the portal signal stimulate net glycolysis directly and/or indirectly, via increased supply of glucose-6-phosphate. The accumulation of glycogen over the first $30 \mathrm{~min}$ of period 2 was minimal in the control and insulin group but was significant $(22 \mu \mathrm{mol} / \mathrm{gram})$ in the portal group. This difference in glycogen accumulation is consistent with the difference in the net retention of glucose equivalents by the liver among these groups over this time period (Fig. 6). These results imply that the net supply of glucose and glucose-6-phosphate limits glyco- 
gen accumulation and that the portal signal facilitates early liver glycogen accumulation via its ability to rapidly stimulate hepatic glucose uptake. The presence of the portal signal maintained net hepatic lactate production over the final 180 min of period 2 (Fig. 6). In contrast, net hepatic lactate production waned over this same time period when hyperinsulinemia was present without the portal signal. This waning of net hepatic lactate production, in the presence of continued net glucose uptake, produced a large disparity in the net retention of glucose equivalents between the insulin and portal groups over the final $150 \mathrm{~min}$ of period 2 . These results suggest that liver glycogen accumulation in response to a fourfold rise in insulin results from the maintenance of increased NHGU coupled with decreased net hepatic lactate production. They also suggest that there is cooperative regulation of liver glycogen accumulation between the portal signal, which produces early accumulation, and insulin, which sustains and maximizes accumulation.

The control of liver glycogen synthesis has been studied and debated for many years (for recent reviews see references 12,39 , and 40). In general, net glycogen synthesis from glucose can occur by either a "push" (increased hepatic concentrations of hexose monophosphates which stimulate glycogen synthesis and glycolysis), "pull" (activation of glycogen synthesis and glycolysis which reduces hepatic concentrations of hexose monophosphates), or some combination of "push" and "pull" mechanisms (42-44). The present study provides some insight into the effects of insulin and the portal signal on control of liver glycogen accumulation by push and pull mechanisms. A fourfold increase in insulin in the absence of the portal signal resulted in activation of liver glycogen synthase before a significant increase in NHGU (i.e., 30 min into period 2). Activation of glycogen synthase in the absence of increased glucose provision to the hepatocyte implies the presence of a pull mechanism. Identification of push and/or pull mechanisms in response to the portal signal is more difficult since stimulation of NHGU and glycogen synthase was observed at the earliest time points (i.e., $15 \mathrm{~min}$ for NHGU and $30 \mathrm{~min}$ for glycogen synthase). However, based on the rapid stimulation of NHGU one can envision that push mechanisms must operate initially in response to the portal signal. This suggests that the portal signal may regulate liver glycogen metabolism primarily via push mechanisms and insulin via both pull and push mechanisms. This would support the concept that the portal signal and insulin work in a coordinated fashion to regulate liver glucose and glycogen metabolism.

In 1987, Adkins et al. (32) observed a reduction in glucose uptake by extrahepatic tissues when hyperglycemia from portal glucose delivery was compared with similar hyperglycemia from peripheral glucose delivery. It was suggested that the portal signal not only enhanced hepatic glucose uptake but might also induce peripheral insulin resistance. In the present study the average rate of glucose infusion was similar among groups during period $1\left(\sim 21 \mu \mathrm{mol} \cdot \mathrm{kg}^{-1} \cdot \mathrm{min}^{-1}\right)$. In the portal group the glucose infusion rate did not increase significantly during period 2 despite the fact that NHGU went from -0.7 $\mu \mathrm{mol} \cdot \mathrm{kg}^{-1} \cdot \mathrm{min}^{-1}$ in period 1 to $\sim-13 \mu \mathrm{mol} \cdot \mathrm{kg}^{-1} \cdot \mathrm{min}^{-1}$ in period 2. This result also suggests that extrahepatic net glucose removal was reduced in response to the portal signal and implies that this signal may regulate glucose uptake by both hepatic and extrahepatic tissues. It would appear that the portal signal produces a coordinated regulation of tissue glucose me- tabolism that ensures adequate provision of glucose to the hepatocyte. It should be emphasized that the decrease in extrahepatic net glucose disposal that was evident in the portal group could not be solely explained by the slightly lower arterial glucose concentrations $(\sim 0.4 \mathrm{mM})$ evident in this group compared with the insulin group (that is, glucose clearance was significantly lower in the portal group).

In this study two factors must be considered that could potentially impact on the interpretation of the results. The first is the estimate of liver glycogen accumulation which by necessity must involve two groups of animals (Table VI). Our estimate is based on the assumption that liver glycogen concentration measured at the end of period 1 reflects the liver glycogen concentration that was present at the end of period 1 in those animals that were studied after period 2. Evidence in support of this assumption comes from the fact that the measured net retention of glucose equivalents by the liver during period 2, tracer estimated rates of glucose incorporation into glycogen (data not shown), and the estimated increment in liver glycogen (Table VI) were not significantly different. In addition, the values for liver glycogen in the group of animals killed after period 1 had a markedly small variance $(154 \pm 3 \mu \mathrm{mol} / \mathrm{gram}$; range $=145-161 \mu \mathrm{mol} /$ gram $)$. The similarity of values among animals was probably due to the fact that the animals were fasted for $42 \mathrm{~h}$ before the study, a duration of fast that results in liver glycogen levels that are at a stable minimum (20). Finally, it should be noted that calculation of the increment in liver glycogen using either the minimum or maximum value given above would not change the conclusions of this study.

A second factor that must be considered when extrapolating the present data to postprandial hepatic glucose metabolism was the presence of hyperglycemia before the experimental period (i.e., between 120 and $210 \mathrm{~min}$ ). The fact that the rates of NHGU in the insulin/portal group from this study are similar to estimates from our previous studies in which hyperglycemia was initiated simultaneously with hyperinsulinemia and the portal signal suggests that the present study design had a minimal impact on the hepatic response $(10,38)$. In addition, the rates of NHGU in the insulin/portal group are similar to rates that have been measured after glucose ingestion $(4,40)$. It should be emphasized that the hyperglycemic control period (period 1) was required to accurately investigate the time course of induction of NHGU in response to insulin and the portal signal. Without preexisting hyperglycemia this would be impossible since a large portion of glucose uptake after the creation of hyperglycemia would reflect equilibration of glucose between the blood and hepatocyte, and not true glucose uptake.

In summary, the portal signal without hyperinsulinemia can induce a rapid shift of the liver into net glucose uptake. This signal can also increase liver glycogen synthase and lead to glycogen accumulation. It would appear that the portal signal exerts its effects on hepatic glucose uptake (and not glucose production) and may regulate liver glycogen synthesis through its ability to increase glucose provision to the hepatocyte. A fourfold rise in insulin, brought about in the presence of hyperglycemia but in the absence of the portal signal, can produce a rate of NHGU that is eventually similar to that seen with the portal signal. However, the onset of action for insulin is significantly slower than that of the portal signal. In contrast to the portal signal, hyperinsulinemia increases NHGU via effects on both hepatic uptake and production. A fourfold rise of insulin 
also produces a marked increase in hepatic glycogen synthase and results in glycogen accumulation. The temporal relationships between NHGU, net hepatic lactate release, and activation of glycogen synthase suggest that push mechanisms primarily drive liver glycogen synthesis in response to the portal signal, whereas both push and pull mechanisms operate in response to insulin. It appears that the response of liver glucose metabolism to the combination of hyperglycemia, hyperinsulinemia, and the portal signal represents a summation of their individual actions.

\section{Acknowledgments}

The authors would like to acknowledge the technical assistance of Wanda Snead and the Hormone Core Laboratory.

This work was supported by National Institute of Diabetes and Digestive and Kidney Diseases grant R01-DK-43706 and Diabetes Research and Training Center grant SP-60-AM20593.

\section{References}

1. Pagliassotti, M. J., and A. D. Cherrington. 1992. Regulation of net hepatic glucose uptake in vivo. Аnпи. Rev. Physiol. 54:847-860.

2. DeFronzo, R. A., E. Ferrannini, R. Hendler, J. Wahren, and P. Felig. 1978. Influence of hyperinsulinemia, hyperglycemia, and the route of glucose administration on splanchnic glucose exchange. Proc. Natl. Acad. Sci. USA. 75: 5173-5177.

3. Sacca, L., M. Cicala, B. Trimarco, B. Ingaro, and C. Vigorito. 1982. Differential effects of insulin on splanchnic and peripheral glucose disposal after an intravenous glucose load in man. J. Clin. Invest. 70:117-126.

4. Abumrad, N. N., A. D. Cherrington, P. E. Williams, W. W. Lacy, and D. Rabin. 1982. Absorption and disposition of a glucose load in the conscious dog. Am. J. Physiol. 242:E398-E406.

5. Ferrannini, E., O. Bjorkman, G. A. Reichard, Jr., A. Pilo, M. Olsson, J. Wahren, and R. A. Defronzo. 1985. The disposal of an oral glucose load in healthy subjects: a quantitative study. Diabetes. 34:580-588.

6. Kelley, D., A. Mitrakou, J. Marsh, F. Schwenk, J. Benn, G. Sonnenberg, M. Arcangeli, T. Aoki, J. Sorensen, M. Berger, et al. 1988. Skeletal muscle glycolysis, oxidation, and storage of an oral glucose load. J. Clin. Invest. 81:15631571.

7. Radziuk, J. 1987. Tracer methods and the metabolic disposal of a carbohydrate load in man. Diabetes Metab. Rev. 3:231-267.

8. Cherrington, A. D., R. W. Stevenson, K. E. Steiner, M. A. Davis, S. R. Myers, B. A. Adkins, N. N. Abumrad, and P. E. Williams. 1987. Insulin, glucagon, and glucose as regulators of hepatic glucose uptake and production in vivo. Diabetes Metab. Rev. 3:307-332.

9. Mitrakou, A., R. Jones, Y. Okuda, J. Pena, N. Nurjhan, J. B. Field, and J. E. Gerich. 1991. Pathway and carbon sources for hepatic glycogen repletion in dogs. Am. J. Physiol. 260:E194-E202.

10. Pagliassotti, M. J., S. R. Myers, M. C. Moore, D. W. Neal, and A. D. Cherrington. 1991. Magnitude of negative arterial-portal glucose gradient alters net hepatic glucose balance in conscious dogs. Diabetes. 40:1659-1668.

11. Insel, P. A., J. E. Liljenquist, J. D. Tobin, R. S. Sherwin, P. Watkins, R. Andres, and M. Berman. 1975. Insulin control of glucose metabolism in man. A new kinetic analysis. J. Clin. Invest. 55:1057-1064.

12. Bergman, R. N., D. T. Finegood, and M. Ader. 1985. Assessment of insulin sensitivity in vivo. Endocr. Rev. 6:45-85.

13. Adkins-Marshall, B., M. J. Pagliassotti, J. R. Asher, C. C. Connolly, D. W. Neal, P. E. Williams, S. R. Myers, G. K. Hendrick, R. B. Adkins, Jr., and A. D. Cherrington. 1992. Role of hepatic nerves in response of liver to intraportal glucose delivery in dogs. Am. J. Physiol. 262:E679-E686.

14. Katz, J., and J. D. McGarry. 1984. The glucose paradox. Is glucose a substrate for liver metabolism? J. Clin. Invest. 74:1901-1909.

15. Newgard, C. B., L. J. Hirsch, D. W. Foster, and J. D. McGarry. 1983. Studies on the mechanism by which exogenous glucose is converted into liver glycogen in the rat. A direct or an indirect pathway? J. Biol. Chem. 258:80468052.

16. Shulman, G. I., L. Rossetti, D. L. Rothman, J. B. Blair, and D. Smith. 1987. Quantitative analysis of glycogen repletion by nuclear magnetic resonance spectroscopy in the conscious rat. J. Clin. Invest. 80:387-393.

17. Shalwitz, R. A., N. V. Reo, N. N. Becker, A. C. Hill, C. S. Ewy, and J. J. H. Ackerman. 1989. Hepatic glycogen synthesis from duodenal glucose and alanine. An in situ ${ }^{13}$ C NMR study. J. Biol. Chem. 264:3930-3934.

18. Shulman, G. I., G. Cline, W. C. Schumann, V. Chandramouli, K. Kuma- ran, and B. R. Landau. 1990. Quantitative comparison of pathways of hepatic glycogen repletion in fed and fasted humans. Am. J. Physiol. 259:E335-E341.

19. Moore, M. C. A. D. Cherrington, G. Cline, M. J. Pagliassotti, E. M. Jones, D. W. Neal, C. Badet, and G. I. Shulman. 1991. Sources of carbon for hepatic glycogen synthesis in the conscious dog. J. Clin. Invest. 88:578-587.

20. Hendrick, G. K., R. T. Frizzell, P. E. Williams, and A. D. Cherrington. 1990. Effect of hyperglucagonemia on hepatic glycogenolysis and gluconeogenesis after a prolonged fast. Am. J. Physiol. 258:E841-E849.

21. Hartley, C. J., and J. S. Cole. 1974. An ultrasonic pulsed Doppler system for measuring blood flow in small vessels. J. Appl. Physiol. 37:626-629.

22. Liljenquist, J. E., G. L. Mueller, A. D. Cherrington, J. M. Perry, and D Rabinowitz. 1979. Hyperglycemia per se (insulin and glucagon withdrawn) can inhibit hepatic glucose production in man. J. Clin. Endocrinol. \& Metab. 48: 171-175.

23. Goresky, C. A., C. G. Back, and B. E. Nadeau. 1975. Red cell carriage of label: its limiting effect on the exchange of materials in the liver. Cir. Res. 36: 328-351.

24. Kadish, A. H., R. L. Little, and J. C. Sternberg. 1968. A new and rapid method for the determination of glucose by measurement of rate of oxygen consumption. Clin. Chem. 14:116-131.

25. Lloyd, B., J. Burrin, P. Smythe, and K. G. M. M. Alberti. 1978. Enzymatic fluorometric continuous-flow assays for blood glucose, lactate, pyruvate, alanine, glycerol, and 3-hydroxybutyrate. Clin. Chem. 24:1724-1729.

26. Brun, C. 1951. A rapid method for the determination of para-aminohippuric acid in kidney function tests. J. Lab. Clin. Med. 37:955-958.

27. Aguilar-Parada, E., A. M. Eisentraut, and R. H. Unger. 1969. Pancreatic glucagon secretion in normal and diabetic subjects. Am. J. Med. Sci. 257:415419 .

28. Morgan, C. R., and A. L. Lazarow. 1963. Immunoassay of insulin: two antibody system. Plasma insulin of normal, subdiabetic, and diabetic rats. Am. J. Med. Sci. 257:415-419.

29. Chan, T. M., and J. H. Exton. 1976. A rapid method for the determination of glycogen content and radioactivity in small quantities of tissue or isolated hepatocytes. Anal. Biochem. 71:96-105.

30. Nuttall, F. Q., and M. C. Gannon. 1989. An improved assay for hepatic glycogen synthase in liver extracts with emphasis on synthase R. Anal. Biochem. 178:311-319.

31. Leevy, C. M., C. L. Mendenhall, W. Lesko, and M. M. Howard. 1962. Estimation of hepatic blood flow with indocyanine green. J. Clin. Invest. 41: 1169-1179.

32. Adkins, B. A., S. R. Myers, G. K. Hendrick, R. W. Stevenson, P. E. Williams, and A. D. Cherrington. 1987. Importance of the route of intravenous delivery to hepatic glucose balance in the conscious dog. J. Clin. Invest. 79:557565.

33. Myers, S. R., D. W. Biggers, D. W. Neal, and A. D. Cherrington. 1991. Intraportal glucose delivery enhances the effects of hepatic glucose load on net hepatic glucose uptake in vivo. J. Clin. Invest. 88:158-167.

34. Allsop, J. R., R. R. Wolfe, and J. F. Burke. 1978. The reliability of rates of glucose appearance in vivo calculated from constant tracer infusions. Biochem. J. 172:407-416.

35. Finegood, D. T., R. N. Bergman, and M. Vranic. 1987. Estimation of endogenous glucose production during hyperinsulinemic-euglycemic glucose clamps. Diabetes. 36:914-924.

36. Cobelli, C., A. Mari, and E. Ferrannini. 1987. Non-steady state: error analysis of Steele's model and developments for glucose kinetics. Am. J. Physiol. 252:E679-E689.

37. Moore, M. C., M. J. Pagliassotti, L. L. Swift, J. Asher, J. Murrell, D. Neal, and A. D. Cherrington. 1994. Disposition of a mixed meal by the conscious dog. Am. J. Physiol. 266:E666-E675.

38. Myers, S. R., O. P. McGuinness, D. W. Neal, and A. D. Cherrington. 1991. Intraportal glucose delivery alters the relationship between net hepatic glucose uptake and the insulin concentration. J. Clin. Invest. 87:930-939.

39. Bergman, R. N., J. R. Bier, and P. M. Hourigan. 1982. Intraportal glucose infusion matched to oral glucose absorption: lack of evidence for "gut factor" involvement in hepatic glucose storage. Diabetes. 31:27-35.

40. Ishida, T., Z. Chap, J. Chou, R. Lewis, C. Hartley, M. Entman, and J. B. Field. 1983. Differential effects of oral, peripheral intravenous, and intraportal glucose on hepatic glucose uptake and insulin and glucagon fractional extraction in conscious dog. J. Clin. Invest. 72:590-600.

41. Gardemann, A. D., H. Strulik, and K. Jungermann. 1986. A portal-arterial glucose concentration gradient as a signal for insulin-dependent net glucose uptake in perfused rat liver. FEBS Lett. 292:255-259.

42. Newsholme, E. A., and C. Start. 1973. Regulation in Metabolism. John Wiley \& Sons, Ltd., England. 186-193.

43. van de Werve, G., and B. Jeanrenaud. 1987. Liver glycogen metabolism: an overview. Diabetes Metab. Rev. 3:47-78.

44. Youn, J. H., and R. N. Bergman. 1990. Enhancement of hepatic glycogen by gluconeogenic precursors: substrate flux or metabolic control? Am. J. Physiol. 258:E899-E906 